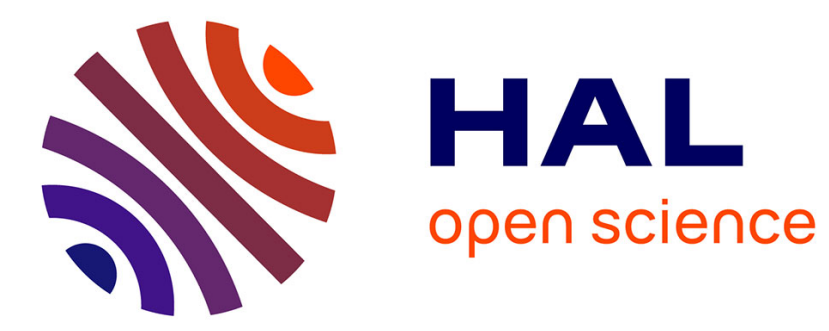

\title{
Ce K-EDGE EXAFS SPECTRUM OF CeO2
}

\author{
K. Asakura, Y. Satow, H. Kuroda
}

\section{To cite this version:}

K. Asakura, Y. Satow, H. Kuroda. Ce K-EDGE EXAFS SPECTRUM OF CeO2. Journal de Physique Colloques, 1986, 47 (C8), pp.C8-185-C8-188. 10.1051/jphyscol:1986834 . jpa-00226156

\section{HAL Id: jpa-00226156 https://hal.science/jpa-00226156}

Submitted on 1 Jan 1986

HAL is a multi-disciplinary open access archive for the deposit and dissemination of scientific research documents, whether they are published or not. The documents may come from teaching and research institutions in France or abroad, or from public or private research centers.
L'archive ouverte pluridisciplinaire HAL, est destinée au dépôt et à la diffusion de documents scientifiques de niveau recherche, publiés ou non, émanant des établissements d'enseignement et de recherche français ou étrangers, des laboratoires publics ou privés. 


\title{
Ce K-EDGE EXAFS SPECTRUM OF $\mathrm{CeO}_{2}$
}

\author{
K. ASAKURA, Y. SATOW ${ }^{*}$ and H. KURODA
}

Research Center for spectrochemistry and Department of Chemistry, Faculty of Science, the University of Tokyo, Hongo, Tokyo 113, Japan

"Photon Factory. National Laboratory for High Energy Physics, Oho-machi, Tsukuba-gun, Ibaragi 305. Japan

The Ce $\mathrm{K}$-edge $(40 \mathrm{keV})$ EXAFS of $\mathrm{CeO}_{2}$ was successfully measured by using Si(553) double crystal monochromator and the synchrotron radiation emitted from the photon Factory wiggler. The energy resolution was estimated to be about $17 \mathrm{eV}$ from the width of the Ce $\mathrm{K}$-edge absorption edge. The distances $8 \mathrm{Ce}-\mathrm{O}$ and $\mathrm{Ce}-\mathrm{Ce}$ were determined to be $2.28(3) \AA$ and $3.38(5)$ \&y using theoretically derived phase shifts. We demonstrated the possibility of elucidating structural parameters from K-edge EXAFS spectra of the atoms with the medium $\mathrm{Z}$ values $(50<\mathrm{Z}<60)$.

\section{INTRODUCTION}

EXAFS spectroscopy has proved to be a powerful tool for the determination of the local structure around a specified atom in polyatomic system. The heavy elements with $Z>50$ have usually been investigated with the EXAFS above $\mathrm{L}_{3}$-edge instead of $\mathrm{K}$-edge for the following reasons ${ }^{1}$ ).

(1) The reflectivity of crystals as well as the intensities of X-ray sources decreases at high photon energies.

(2) The lifetime broadening of K-edge becomes appreciable for the heavy atoms.

For the elements with medium atomic numbers $(50<z<60)$, however, the energy seperation of $\mathrm{L}_{3}$ and $\mathrm{L}_{2}$ edges is considerably small(less than $600 \mathrm{eV}, \mathrm{i} . e . \mathrm{k}<12 \AA^{-\top}$ ) and thus EXAFS oscillation can not be obtained over the sufficient data range. This shorter data range limits the precision of EXAFS. Hence the $\mathrm{k}$-edge EXAFS measurements are desirable but seldom has been carried out on these elements for the above-mentioned reasons. However the lifetime broadening of those elements is less than $\left.15 \mathrm{ev}^{2}\right)$ and it is possible to measure their K-edge EXAFS spectra considering the energy resolution necessary for EXAFS measurement to be $10-20 \mathrm{eV}$. The difficulty exists in a technical problem. In this work we shall show that it is possible to measure the Ce $\mathrm{K}$-edge EXAFS spectrum of $\mathrm{CeO}_{2}(40 \mathrm{keV})$ with a good $\mathrm{S} / \mathrm{N}$ ratio by using wiggler radiation and $\mathrm{Si}(553)$ double crystal monochromator.

\section{EXPERIMENTAL}

Ce K-edge EXAFS spectrum was measured at the wiggler beam line $14 \mathrm{~A}$ of Photon Factory (KEK-PF). The critical wavelength of the radiation is $0.6 \mathrm{~A}$ at $5 \mathrm{~T}$ wiggler operation 3 ). The $\mathrm{X}$-ray was monochromatized by Si(553). double crystal monochromator, which covers 


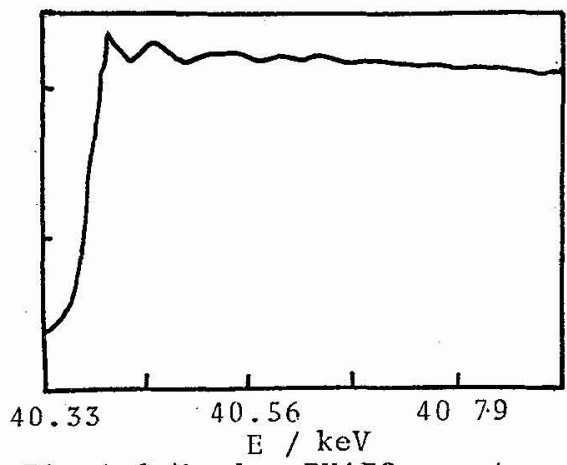

Fig. 1 CeK-edge EXAFS spectrum

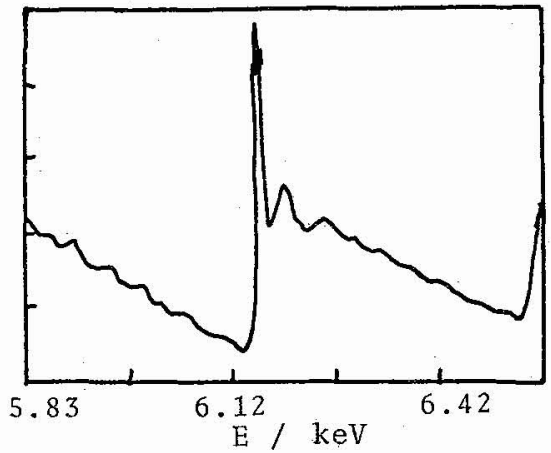

Fig. 3 Ce $L_{2}$-edge EXAFS spectrum

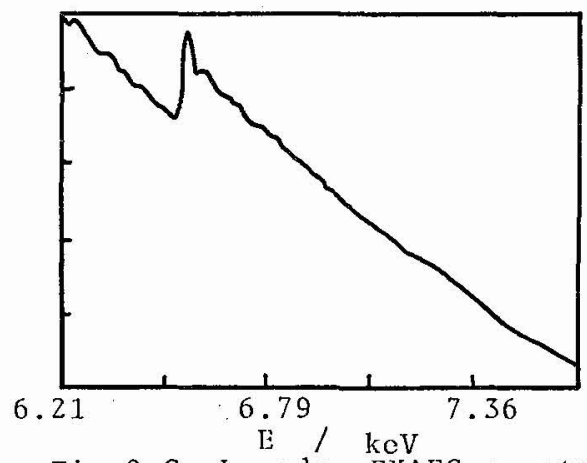

Fig. 2 Ce $\mathrm{L}_{1}$-edge EXAFS spectrum

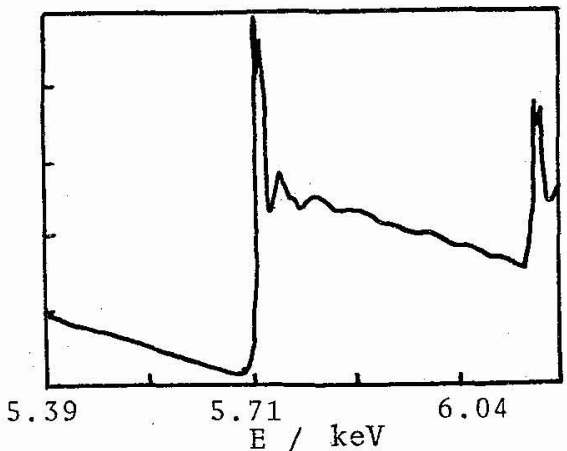

Fig. 4 Ce $\mathrm{L}_{3}$-edge EXAFS spectrum

the energy range $23 \mathrm{keV}-85 \mathrm{keV}$. The details of the instrument are descibed elsewhere 4 )5). The parallelism of two cxystals and the translation of the second crystal were finely adjusted at each data point to keep the beam from going away. The $I_{0}$ and $I$ were monitored by $\mathrm{Xe}$ - or $\mathrm{Kr}$-filled ionization chambers.

The EXAFS spectra above $\mathrm{L}_{1}, \mathrm{~L}_{2}$ and $\mathrm{L}_{3}$-edges were recorded at $\mathrm{BL}-10 \mathrm{~B}$ of Photon Factory ${ }^{6}$ ).

\section{RESULTS AND DISCUSSION}

The $\mathrm{K}$-edge absorption spectrum of $\mathrm{CeO}_{2}$ is shown in Fig.1. The fine structure extends $500 \mathrm{eV}$ above the edge. Figures 2-4 show the $\mathrm{L}_{1-}, \mathrm{L}_{2-}$ and $\mathrm{L}_{3}$-edges EXAFS spectra. The fine structures in the pre-edge region of $\mathrm{L}_{1}-$ and $\mathrm{L}_{2}$-edge absorption spectra are the $\mathrm{L}_{2}$ - and $L_{3}$-edge EXAFS oscillations which extend over the $L_{1}$-edge and $L_{2}$-edge, respectively. The $\mathrm{L}_{3}$-edge EXAFS oscillation is truncated by $\mathrm{L}_{2}$-edge at $6160 \mathrm{keV}$ and the $\mathrm{L}_{2}$-edge EXAFS oscillation is in turn truncated by $\mathrm{L}_{1}$-edge at $6550 \mathrm{eV}$. Thus the three L-edges were interferred with each other.

Comparing $\mathrm{K}$-edge absorption spectrum with the $\mathrm{L}_{1}$-edge one as shown in Fig.2, the first edge peak of K-edge absorption is diminished to some degree due to the lifetime broadening of the core hole. The energy resolution estimated from the width of the absorption edge 2 ) is $17 \mathrm{eV}$ which is in good agreement with the theoretically-calculated lifetime broadening 23 . Figure 5 shows the $\mathrm{k}^{3}$-weighted K-edge EXAFS oscillation together with L-edges EXAFS oscillations. Figure 6 shows the Fourier transforms of the EXAFS oscillations of Fig.5. The first peak is corresponding to the $\mathrm{Ce}-\mathrm{O}$ and the second one is to the $\mathrm{Ce}-\mathrm{Ce}$. 

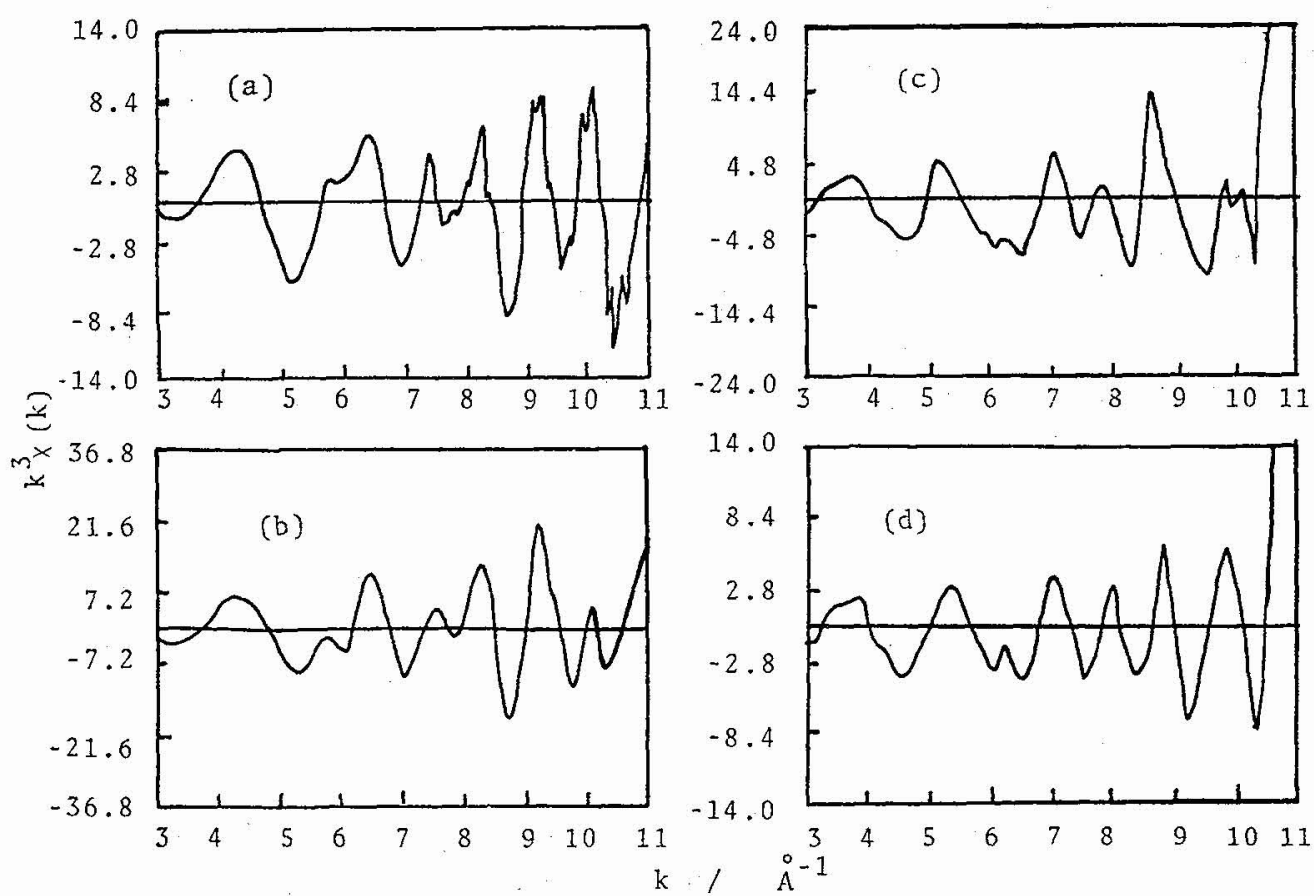

Fig. $5 \mathrm{~K}^{3} \times(\mathrm{k})$ of $\mathrm{K}$-edge(a), $\mathrm{L}_{1}$-edge(b), $\mathrm{L}_{2}$-edge (c), and $\mathrm{L}_{3}$-edge of $\mathrm{CeO}_{2}$

By correcting the phase shifts by using the theoretically-derived ones 7 ), the distances of the $\mathrm{Ce}-\mathrm{O}$ and $\mathrm{Ce}-\mathrm{Ce}$ bondings are $2.28(3) \AA$ and 3.88(5) \&, respectively. The distances of $\mathrm{Ce}-\mathrm{O}$ and $\mathrm{Ce}-\mathrm{Ce}$ determined from crystallographical data are $2.32 \AA$ and $3.82 \AA$, respectively. Thus we conclude that it is possible to elucidate the structural parameters from Ce K-edge EXAFS. The core hole lifetime broadening diminished the amplitudes of the peaks appearing in the Fourier transformation of the $C e$-edge EXAFS compared to those of $L_{1}$-edge one.

The merits of the K-edge EXAFs measurement for the atoms with medium atomic numbers are summarized as follows.

(1) The K-edge spectrum is not interferred with by the other absorption edges and the long data range is available for the data reduction.

(2) The absorption of the other elements are very low because the photon energy is higher than $30 \mathrm{keV}$ and the investigation of the dilute system is possible in a transmission mode.

(3) EXAFs is described by the simple formalism because the only one transition to the p-state is allowed.

References

1) P.Rabe, G.Tolkehn and A.Werner, J.Phys.C 12, 899(1979).

2) B.K.Agarwal, "X-ray Spectroscopy", Springer-Verlag, Heiderberg, (1979).

3) T.Yamakawa et al., Nucl. Instr. and Meth., A246, 32(1986).

4) M.Ando, Y.Satow, H.Kawata, P.Spieker, and S.Suzuki, Nuclear Instr. and Meth., A246, 144(1986). 


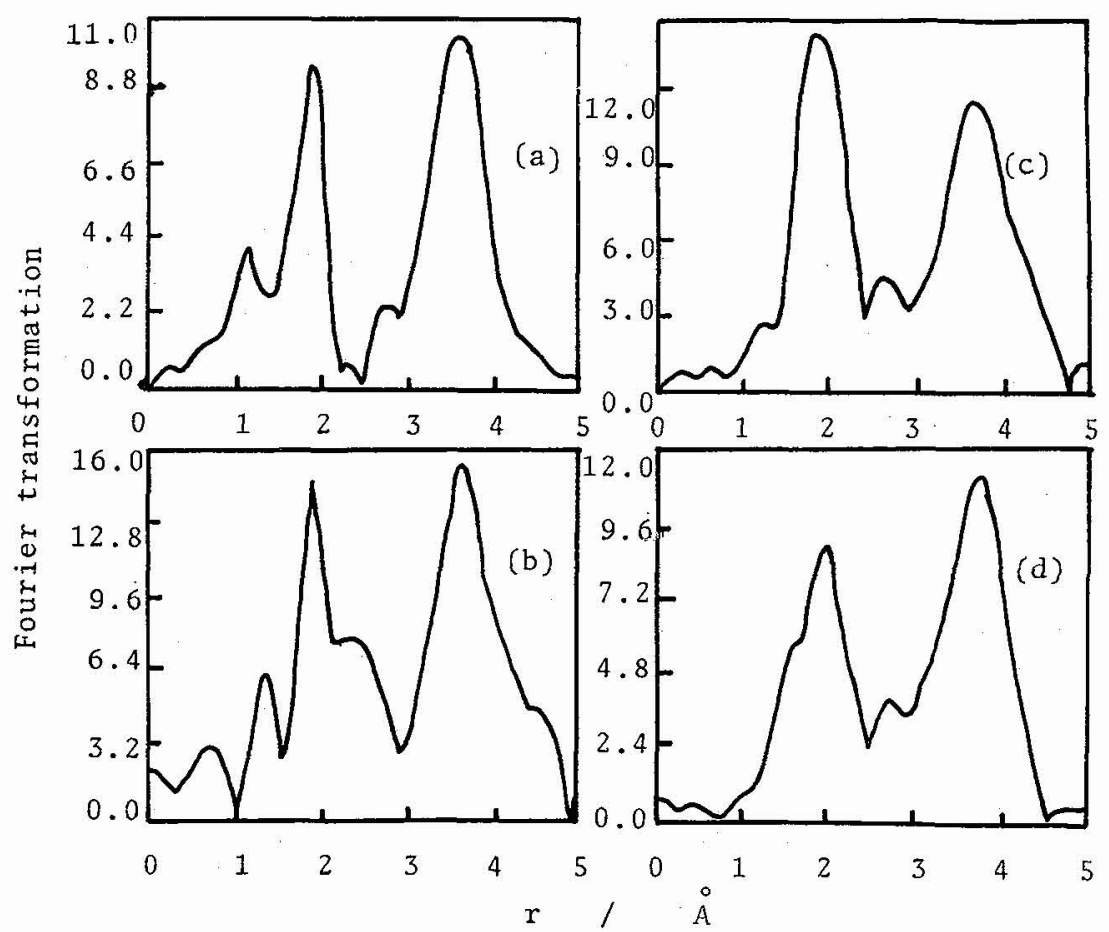

Fig.6 Fourier transforms of $\mathrm{K}$-edge (a), $\mathrm{L}_{1}$-edge (b), $\mathrm{L}_{2}$-edge (c), and $\mathrm{L}_{3}$-edge (d).

5) Y.Satow et al., to be published.

6) H.Oyanagi, T.Matsushita, M.Ito, and H.Kuroda, KEK Report, $1984,83-30$.

7) B.K.Teo and P.A.Lee, J.Am.Chem.Soc., 100, 2815(1979). 